

\section{Back Cover}

Marion H. Emmert, Amanda K. Cook, Yushu J. Xie, and Melanie S. Sanford*

Palladium/pyridine catalyst systems for efficient, nondirected $\mathrm{C}-\mathrm{H}$ oxygenation of simple arenes are described by M. S. Sanford and co-workers in their Communication on page $9409 \mathrm{ff}$. In the picture, Goldilocks discovers three bowls with pyridine, just as she discovers three differently sized bowls of porridge in the fairy tale. Only the "just right" amount of pyridine results in the efficient formation of PhOAc from $\mathrm{PhH}$. Furthermore, the selectivity and substrate scope are improved.

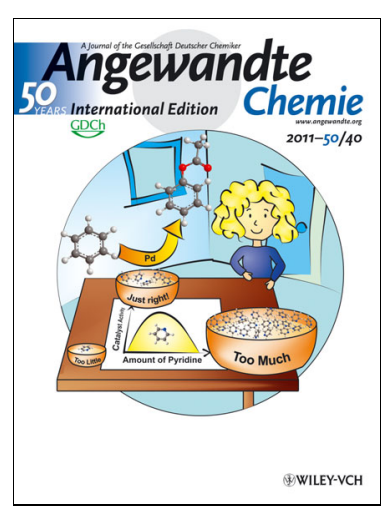

